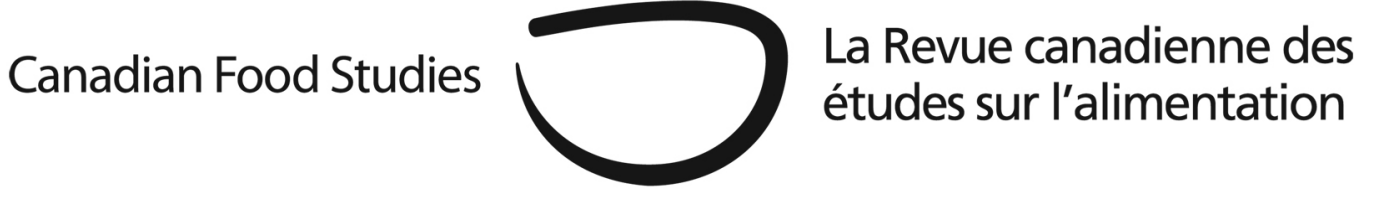

Original Research Article

\title{
Land-based programs in the Northwest Territories: Building Indigenous food security and well-being from the ground up
}

Sonia D. Weschea, Meagan Ann F. O'Hare-Gordon ${ }^{b}$, Michael A. Robidoux ${ }^{c}$, and Courtney W. Mason ${ }^{d}$

${ }^{a}$ Assistant Professor, Department of Geography, Environment and Geomatics, University of Ottawa swesche@uottawa.ca

${ }^{\mathrm{b}}$ MA Student, School of Human Kinetics, University of Ottawa

'Professor, School of Human Kinetics, University of Ottawa

${ }^{\mathrm{d}}$ Canada Research Chair, Rural Livelihoods and Sustainable Communities, Department of Tourism Management, Thompson Rivers University

\section{Abstract}

Food security in Canada's North is complex, and there is no singular solution. We argue that land-based wild food programs are useful and effective in contributing to long-term food security, health, and well-being for Indigenous communities in the context of changing environmental conditions. Such bottom-up programs support cultural continuity and the persistence of skills and knowledge that, over time, increase local food security and food sovereignty. This paper (a) highlights the link between observed environmental changes and wild food procurement in two Indigenous communities in the Northwest Territories, (b) compares and discusses the impacts of two collaboratively developed, community-based programs to improve foodways transmission and capacity for wild food procurement, and (c) identifies lessons learned and productive ways forward for those leading similar efforts in other Indigenous communities.

Keywords: environmental change, wild food, community-based research, community food security, Indigenous health and well-being, northern Canada 


\section{Introduction}

Environmental changes are being documented on a global scale, with northern regions experiencing some of the most significant and rapid shifts. Global trends include increasing atmospheric and ocean temperatures, shifting vegetation zones, thawing permafrost, declining sea ice, and rising sea levels (ACIA, 2005); however, the nature of these changes and their impacts varies regionally. Indigenous peoples ${ }^{1}$ are particularly vulnerable, as they rely on the integrity and continuity of local ecosystems for wild food ${ }^{2}$ and to maintain vital social and cultural practices. In northern Canada, cumulative exposures to social and environmental stressors are challenging the capacity of remote communities to attain food security. Since European contact, and particularly over the last half-century, colonial processes have disrupted historically-embedded social and cultural norms and dispossessed Indigenous groups of their traditional lands and resources (Reading \& Wien, 2009).

The resulting nutrition transition has led to a shift from former reliance on nutrient-rich wild food harvested from the land towards greater consumption of market food purchased from the store, which is often highly processed and of lower nutritional quality. This has serious implications for health and well-being (Kuhnlein, Receveur, Soueida, \& Egeland, 2004; Loring \& Gerlach, 2009). The nature of the mixed diet presents unique challenges for addressing food security. Accordingly, northern food security, while not a new issue, is increasingly being recognized as a multi-faceted issue that requires urgent attention (Council of Canadian Academies, 2014).

In remote northern communities, market foods provide some level of food security; however, their quality and availability relies on the continuity of costly transportation systems that are vulnerable to global economic influences, they are expensive for individuals to purchase, and they do not replace the foundational socio-cultural roles played by local wild foods (Gerlach \& Loring, 2013). At the same time, the procurement of wild foods, which historically provided the basis for survival in these regions, is challenged by a combination of increasing costs for harvesting, inflexible regulatory frameworks, environmental change, and disruption of intergenerational knowledge transmission processes. This has led to lower wild food use among younger generations (Kuhnlein \& Receveur, 2007; Receveur, Boulay, \& Kuhnlein, 1997). As food insecurity reaches critical levels in northern Canada and becomes more of a focus of research and discussion, northerners continue to recognize the value of wild foods for diet and health, as well as for socio-cultural well-being. They are also advocating for mechanisms that help to revitalize their food cultures by reviving and strengthening wild food practices (Fillion,

\footnotetext{
${ }^{1}$ We use the term "Indigenous" to refer collectively to First Nations, Métis, and Inuit peoples in the Canadian context. However, when referring to a specific Indigenous group, we use their own self-appellation (e.g., Dene or Métis peoples) to avoid representing these distinct cultures as a homogeneous group.

${ }^{2}$ In this paper, “wild food” is synonymous with "traditional food” and "country food”, and includes both plants and animals harvested from the northern environment for consumption (e.g., moose, geese, fish, and berries).
} 
Laird, Douglas, Van Pelt, Archie, \& Chan, 2014; Loring \& Gerlach, 2009; Organ, Castleden, Furgal, Sheldon, \& Hart, 2014; Skinner, Hanning, Desjardins, \& Tsuji, 2013).

Food security in Canada's North is complex, and there is no single solution. We argue that land-based ${ }^{3}$ wild food programs are useful and effective in contributing to long-term food security for Indigenous communities in the context of changing environmental conditions. Our objectives are to (a) highlight the links between observed environmental changes and wild food procurement in two Indigenous communities in the southern Northwest Territories, (b) compare and discuss the implications of two collaboratively developed, community-based programs to improve capacity for wild food procurement, and (c) identify lessons learned and productive ways forward for communities. The two research sites, Fort Resolution and Fort Providence, are small Dene-Métis communities located in the southern Northwest Territories in the central Mackenzie River Basin, in what is known as Denendeh (the land of the people). In both cases, a combination of climate change and commercial resource development, among other stressors, is impacting the surrounding traditional territory and affecting the ability of community members to procure wild food.

We focus here on the impacts of environmental change on wild food procurement, but recognize that this is only one aspect of a more complex issue; thus, we place our analysis in the context of a range of other stressors. We first outline our methodology, followed by an overview of the changing environmental and socio-economic contexts of the region and links to food security. Next, we describe the land-based programs implemented in both communities as an adaptation response to re-empower local youth and contribute to healthier diets. We then present key lessons learned from this process, followed by insights on how these lessons might apply in other northern locales.

\section{Methodology}

The development and implementation of this research was guided by Indigenous methodologies (IM). This fostered a collaborative process where Indigenous perspectives and ways of knowing are central. Throughout the research process, we worked with band councils, Dene and Métis Elders, land-users, and community members to follow established protocols and collectively define the research objectives in a way that reflected community values and priorities. Using this partnership approach, we worked with our community partners throughout the research process (Kovach, 2010; Smith, 1999), beginning with defining important community issues and jointly shaping the research questions. IM and other participatory community-based methodologies offer a positive way to help make power relationships in research processes more equitable, while empowering Indigenous participants (Alfred, 2005; Bishop, 2005). Such processes also

\footnotetext{
${ }^{3}$ The "land" is a commonly-used term in the north that describes the surrounding environment in a holistic manner. Thus, "land-based" wild food programs include harvests from the land, water and air.
} 
help to address community interests and ensure that sensitive material is handled appropriately (Battiste \& Henderson, 2000).

The data used here derives from research projects related to a) environmental change and b) wild food procurement with both communities since 2004. In both cases, researchercommunity relationships were initially built around participatory projects focused on documenting and understanding changing environmental conditions. Initial relationships were established with the First Nations Band Councils in the respective communities, through primary liaison with Environment/Natural Resources Managers. The partnerships expanded to include representatives from the hamlets, local Métis associations, and schools, among others.

Perspectives on environmental change in the Fort Resolution area were documented in 2005-06 using a series of 33 semi-structured interviews with land-users and Elders that were facilitated and, where needed, translated by a local research assistant. This also involved on-the-land field visits and participant observation (Wesche, 2009; Wesche \& Armitage, 2006; Wesche \& Armitage, 2010).

Since 2012 we undertook similar activities to understand environmental change in the Fort Providence area, conducting three interactive community meetings and 12 semi-structured interviews with local land-users and Elders. In both cases, the initial research question examined how local people were experiencing and tracking environmental change, what the impacts were (with a key focus on local land-use), and what kind of adaptive response was in place. We also worked with natural science scholars and researchers to achieve a more holistic understanding of environmental change in both locations (Brock et al., 2010; Wolfe et al., 2007).

Through these existing researcher-community relationships, community-identified interests around wild food procurement emerged in both Fort Resolution and Fort Providence. This led to their inclusion in a subsequent multi-community project to implement communitygenerated food security interventions in the north and evaluate their impact on various factors that support food security and community well-being (e.g., knowledge sharing, cultural continuity, social networks, and food access). Data from these recent land-based initiatives derives from our experience in developing partnerships with communities, supporting program implementation, and participating in program activities since 2012. This includes quarterly meetings (telephone and face-to-face); semi-structured interviews (32) with school Principals and staff members, Elders, and land-users; multiple researcher visits to the communities; participation of research team members in coordinating land-based programs; and engagement in local wild food practices. In all cases, local research assistants were engaged to help plan and implement the research activities.

Ethics approval was granted by Wilfrid Laurier University for the 2005-06 research and by the University of Ottawa for the subsequent components. Northwest Territories research licenses were granted by the Aurora Research Institute. Consent forms were used, and only those individuals who agreed are referenced by name in publications. All personal and telephone interviews were transcribed verbatim, and notes from focus groups and other activities were also transcribed. The environmental change data was coded through an iterative process led by one 
team member, and the programs data was analyzed thematically by two other team members who had collected the data. Preliminary results were presented to and verified by community members using both public forums and one-on-one discussions, and resulting draft publications were provided to community representatives for feedback prior to submission. Representative excerpts from the interview transcripts are presented below ${ }^{4}$.

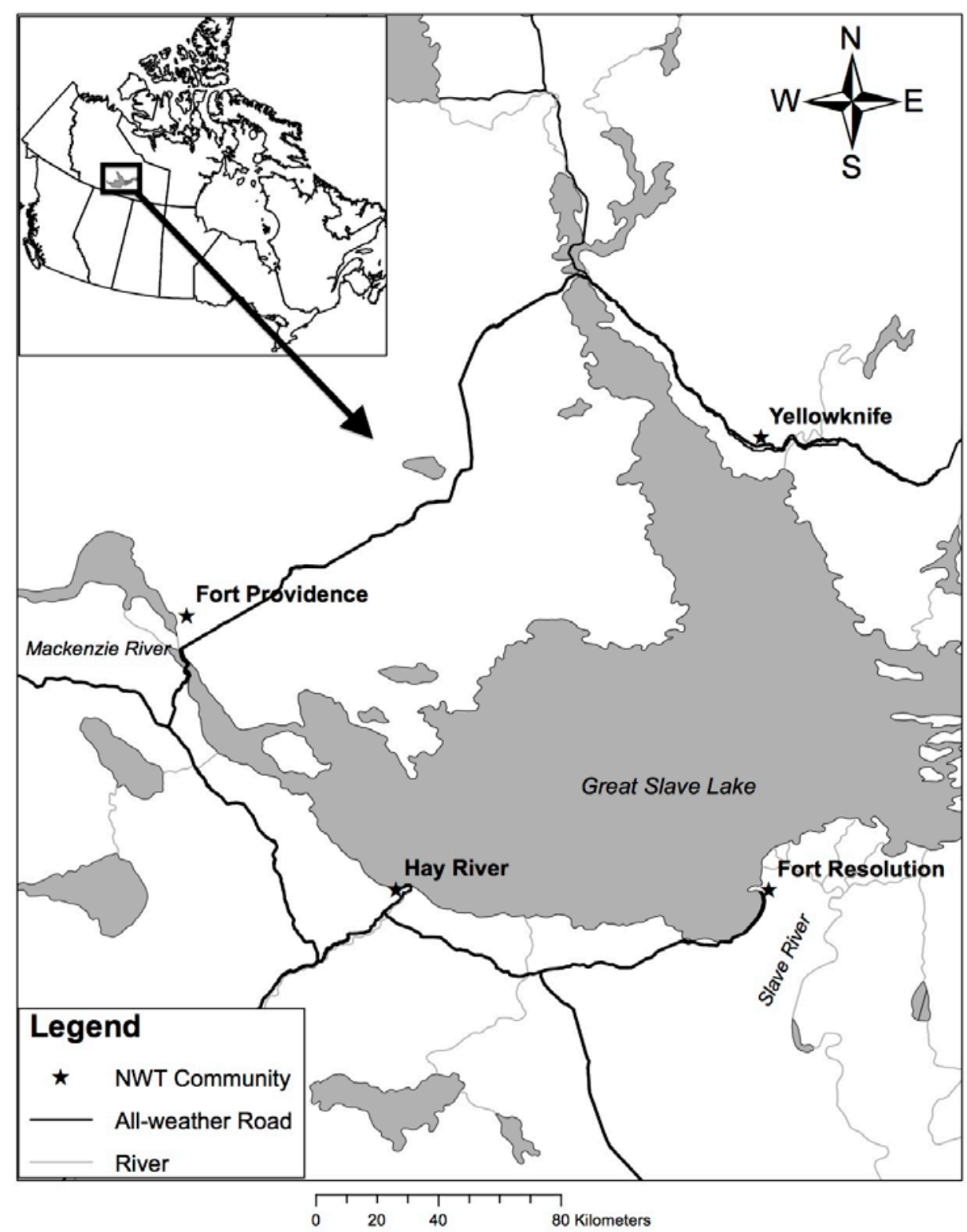

Figure 1: Location of the case study sites: Fort Resolution and Fort Providence, Northwest Territories, Canada

\footnotetext{
${ }^{4}$ All quotations from the 2005-06 research are found in Wesche, 2009.
} 


\section{Community Profiles: Fort Resolution (Deninu Kue) and Fort Providence (Zhahti Kue)}

The communities of Fort Resolution and Fort Providence are both located in the southern Northwest Territories, Canada, above the Alberta border in the central Mackenzie River Basin (Figure 1). Both are small Dene-Métis communities, with Fort Resolution residents being of primarily Chipewyan Dene heritage and Fort Providence residents being primarily of Slavey Dene heritage.

The hamlet of Fort Resolution $\left(61.17^{\circ} \mathrm{N}, 113.67^{\circ} \mathrm{W}\right)$ is located on the south shore of Great Slave Lake near the mouth of the Slave River. The community is home to a population of 480, 90 percent of which is Indigenous (Northwest Territories Bureau of Statistics, 2011c). Settlement in the area was linked to fur trade activity beginning as early as 1786 . The settlement developed into a central node in the northern trading system due to its strategic location at the mouth of the Slave River (Smith, 1982). A mission and orphanage were established later (1858 and 1903, respectively), and the orphanage was converted to a residential school in 1909. A convent and hospital were added in 1939, offering centralized services for many people in the Great Slave Lake region (Fumoleau, 2004). The late 1960s saw the completion of a road connection to the community and new employment opportunities at the nearby Pine Point lead and zinc mine (open 1964-1988), both of which had major socio-economic impacts on Fort Resolution. At present, Deninu Kue First Nation is one of four Akaitcho Territory (Treaty 8) bands involved in treaty and self-government negotiations.

Fort Resolution residents continue to rely heavily on the resources found in and around the three main river systems in their traditional territory_-Slave, Talston and Little Buffalo-as well as Great Slave Lake itself and the shallow ponds found in the Slave River Delta. Common wild foods include moose, bison, muskrats, beavers, rabbits, geese, ducks, ptarmigans, and several species of freshwater fish (e.g., lake whitefish, northern pike, walleye, burbot, longnose sucker, lake trout). Caribou are also hunted periodically, but require long-distance travel from the community.

The hamlet of Fort Providence $\left(61.35^{\circ} \mathrm{N}, 117.66^{\circ} \mathrm{W}\right)$ is located on the east bank of the Mackenzie River, approximately 75 kilometers downriver from the outflow at Great Slave Lake. The community is home to a population of 778, 93 percent of which is Indigenous (Northwest Territories Bureau of Statistics, 2011b). The settlement was established with the building of an orphanage and mission in 1867, followed by a Hudson Bay fur trading post (Hamlet of Fort Providence). It has long acted as a hub for goods and people being transported up and down the Mackenzie River. Since 1968, the Mackenzie Highway has facilitated travel to nearby communities (including Yellowknife) and southern Canada, resulting in substantial and diverse impacts on the community. Recent advancements in governance frameworks have led the Deh Gah Got'ie' Dene Council to join with nine ${ }^{5}$ other First Nations and Métis Councils to

\footnotetext{
${ }^{5}$ The Dehcho Process was initiated in 1999 with 13 members, three of which have since withdrawn.
} 
participate in self-governance, land and resource negotiations with the Government of Canada (Treaties 8 and 11).

Fort Providence residents rely heavily on surrounding water resources for accessing harvesting areas. These include the Mackenzie River, Great Slave Lake, and the many small lakes and streams found in the low-lying Great Slave Lake Plain and the Horn Plateau area that make up their traditional territory. Fort Providence residents maintain many traditional cultural practices, and continue to rely in large part on wild foods, including moose, caribou, rabbits, geese, ducks, and several freshwater fish species (e.g., lake whitefish, northern pike, walleye, burbot, longnose sucker, lake trout). Bison have also been available in the area since 1963 when a protected herd was established in the newly formed Mackenzie Bison Sanctuary; however, only a limited number of local residents commonly eat them. Trapping fur-bearing mammals, such as marten, muskrat, and beaver is also an important economic and cultural activity.

\section{Results: Food security and environmental change}

While market foods now form a significant component of the diet, Indigenous northerners remain connected to the land, and multiple aspects of wild food procurement (e.g., nutritional, cultural, social, economic) are key to cultural continuity and well-being. Wild foods often play a key role in achieving food security, namely "when all people, at all times, have physical, social and economic access to sufficient, safe and nutritious food to meet their dietary needs and food preferences for an active and healthy life” (FAO, 1996, section 2, para 1). This concept is linked to other related concepts such as "nutrition security" (access to essential nutrients) and "food sovereignty" (decision-making power over food systems), both of which apply in the northern Indigenous context (Council of Canadian Academies, 2014). It is imperative to recognize that food security is not just about having food on the table, but also encompasses how people think about and approach food procurement and consumption. Thus, possessing appropriate and adequate knowledge combined with having collective control and sovereignty over food systems are both critical (Desmarais, 2015). Foodways transmission, namely the manner and mechanisms by which food-related knowledge is shared and learned within families and societies is a key component of this process (Ruelle \& Kassam, 2013).

Food security relies on four key pillars, each of which is affected by multiple factors. These include: availability (amount and diversity of traditional food species on the land and/or market foods in the store), accessibility (amount of money available to purchase harvesting equipment or market foods; physical ability to reach harvesting areas or stores), quality (nutritional value, food safety and cultural acceptability), and use (knowledge and skills for food procurement) (Nunavut Food Security Coalition, 2014; Wesche \& Chan, 2010). The stability of food resources over time is also a key parameter. A number of stressors, both historical and contemporary, are impacting northern food security. First we focus on the direct role of rapid 
environmental change as a key contemporary northern stressor that exerts significant impacts on wild food systems. Thereafter, additional stressors are also addressed to provide a holistic perspective.

\section{Regional environmental change}

Environmental change has considerable impacts on all four pillars of food security. The availability, accessibility, and quality of wild food are all influenced directly by changing conditions. For example, caribou may change migration patterns making them less available in some areas; thin ice may make harvesting areas less accessible, and warming temperatures can enable previously unknown illnesses to establish in the area, affecting animal health and thus reducing meat quality. The use pillar is influenced indirectly by environmental change. For example, changing ice conditions may limit land-use at certain times, reducing opportunities for intergenerational knowledge transfer to youth. This limits the development of skills and knowledge for safe and effective wild food procurement.

These environmental change trends are being experienced in both Fort Resolution and Fort Providence, where Indigenous livelihoods are linked to climate, weather, and ecosystems. Although each locale has its unique context, both communities are located at similar latitudes on or near Great Slave Lake, and thus are broadly influenced by similar climatic and hydrological conditions as well as non-point source pollutants. The Mackenzie River Basin (MRB) is undergoing a general warming trend and seasonal shifts in precipitation and evapotranspiration, which will continue to impact hydrological parameters (Yip, Burn, Seglenieks Pietroniro, \& Soulis, 2012). Accordingly, local residents have observed significant changes in climatic phenomena over the past half-century relating to temperature, precipitation, seasonality, and wind. Two Fort Resolution Elders, Denise McKay and Gabe Yelle, reported the following:

To me, everything started changing from 1960 - even the weather, even the snow. The weather pattern has shifted dramatically.

March used to be nice but windy, and then spring would begin in April when the weather started to warm. Recently, we have had some long cold springs, which did not used to happen.

Climate-driven impacts on the hydrological regime of the upper Mackenzie Basin affect water quantity, timing of flow, and water quality downstream (Brock et al., 2010). Local residents have observed changes such as: more variable river discharge, lower water levels, delayed and more variable ice freeze-up, thinner and more unstable ice, earlier and more variable ice break-up, and increased sediment in river and lake water. These changes can affect land-user access to harvesting areas (e.g., reduced boat access to fishing and hunting areas, safety concerns due to ice and weather conditions) as well as wildlife health (e.g., due to altered habitat conditions). Angus Beaulieu, long-time land user, local Fort Resolution historian, and Elder noted: 
The ice used to be thicker in the rivers and lake. I used to set a net behind Moose Deer Island in the 50s to 70s and the ice was over six feet deep. Now a fisherman's lucky if he finds two feet of ice.

Resource development in different parts of the MRB also influences local environmental conditions. Both upstream development, such as the Alberta Oil Sands and Peace River hydroelectric operations, as well as more localized activities like the historic Pine Point lead and zinc mine and highway development since the 1960s, including the recently constructed bridge over the Mackenzie River, combine with climate change to effect multiple impacts on wildlife and local harvesting activities. This is highlighted by Fort Providence Elder Denise Trudeau:

There's less moose around, less of the big game around. Especially now with the highways, the transportation. The highways, in particular, go through some moose or buffalo sanctuaries. It drives them away.

Species availability may be compromised due to habitat changes that result in increased wildlife mortality or shifting migration routes. For example, Fort Resolution land-user Don Balsillie has noticed changes in the migratory patterns of geese, for which the nearby delta has long been a sanctuary:

You don't see as much migratory birds coming through the delta. ... But what I have noticed is the birds that do come through ... they are coming a bit later because of the weather conditions. They are staying a little bit longer.

Similarly, Balsillie indicated that warmer water temperatures in Great Slave Lake cause fish to move and congregate in different areas:

The last number of years that I've been out there fishing each year [the fish have] started to make some changes in their habits of travel - because of the temperature of water, because [of] the late spring. So, everything is evolving.

Increased incidence and severity of fires leads to periodic impacts on local wildlife. Two Fort Providence school staff members, Nancy Francis and Greg Wright, commented on the particularly prolific 2014 fire season:

Last summer, the forest fires drove the animals away, too. The moose, the rabbits, whatever. They're hardly any left around where we hunt because of it. They might be starting to come back now, 
but those fires made it hard to go out hunting when they were burning and now because everything's [the animals] all gone now. ....and then the forest fires. That's another one that drives the game away. And in particular last summer we had lots of fire... and especially in and around our area, there. So there is less small game and less for the wolves and that to prey on. They are after the big game now.

Changing conditions also challenge travel safety and physical access to particular hunting and gathering areas. For example, Fort Providence land-users Theodore Matto and Rudolph Landry have observed a combination of increased water levels, delayed ice freeze-up, heavy snow, and warm temperatures, all of which limit travel by snowmobile:

The weather has really changed. It doesn't really freeze over solid enough to trust a skidoo going in there. Even in the cut-lines, in some places, it isn't even frozen.

Now the climate is getting warmer too.... And underneath the ice is just water, under the snow. Even all these lakes have overflowed. You have to watch [out].

At the same time, while certain species may be both available and accessible, changing conditions can impact the quality and safety of the meat. For example, residents of both communities have reported concerns about changing meat texture, increased presence of abnormalities such as tumours in fish, and the ongoing presence of diseases like anthrax in bison, whose outbreaks are influenced by environmental conditions. Fort Resolution Elder Denise McKay noted:

The fish meat is different for me. ... Sometimes the [flesh is] just soft, so that's different. A long time ago the meat was just nice.

The nature of the abovementioned observations reflects the importance of traditional knowledge in identifying and responding to environmental challenges. Such knowledge is rooted in a specific localized environment and is gained over many years of intimate, place-based interaction. The level of knowledge of an individual or group is directly linked to wild food use, as one must know when, where, and how to travel safely and to locate, harvest, and prepare wild foods. Local residents in both communities highlighted the need for such knowledge systems to be perpetuated and transferred to younger generations. Fort Resolution land-users Harvey Mandeville and Kenneth Delorme noted the following:

Yeah, you pretty well have to be careful. You have to know your way around. A guy can’t just take off like that if you don't know this country. 
Land use is changing. There's a few people trying to get back into using the land and stuff. [Some have] never been on the land before, maybe, but their parents had. Some of it is being lost. It could be taught to them, re-taught to them or saved.

Continued evolution and transmission of relevant knowledge and skills can mitigate these challenges by enabling new forms of access and increased ability to use a range of wild food products. With an in-depth base of traditional knowledge and experience, some land users are able to adapt their practices to ensure both safety and success on the land (e.g., delay hunting trips, change travel patterns, carry safety equipment). They may also adopt new ways (or re-learn old ways) of harvesting, preparing, and consuming under-utilized species or parts of currently harvested animals (e.g., bone marrow, organs) or more recently available species (e.g., those moving into the area as their ranges shift due to climate change).

\section{Socio-Cultural and Economic Stressors}

From a food security perspective, consistent access to healthy foods, especially culturally appropriate local foods, is a considerable challenge for both communities. The prevalence of market food use is high, in part due to its greater convenience, variety, and ease of preparation. The uncertain availability, accessibility, and quality of wild foods also encourage the consumption of market foods. While both communities have all-weather road access ${ }^{6}$, each is located several hundred kilometers from the nearest urban area, thus living costs (e.g., food, equipment, fuel, electricity) remain high. Food prices are approximately 31 percent higher in Fort Providence and 41 percent higher in Fort Resolution than in Yellowknife (Northwest Territories Bureau of Statistics, 2011a). The availability and quality of fresh produce and meats is often limited, as food shipments generally come in once a week and stock is quickly depleted. Road access to the communities can also be unpredictable in winter due to weather. Community members with limited financial means tend to rely on staple goods purchased at community stores, rather than travelling to the larger centres of Yellowknife or Hay River for cost savings and increased selection. Thus, due to economic constraints, food availability, and changing food preferences, many residents often have no choice but to purchase cheaper foods with longer shelf lives, which tend to be higher in fat, sugar, and additives, while having lower nutritional value (Receveur et al., 1997; Pal, Haman, \& Robidoux, 2013).

Changing environmental conditions induced by climate change and industrial (largely resource-driven) development place added pressures on communities that are already working to adapt to a range of other stressors. Socio-cultural transitions occurring in the context of modernization are further challenged by the knowledge gaps left by the colonial education system. All of these stressors impact food security in a range of ways. Over the past century,

\footnotetext{
${ }^{6}$ Until the Deh Cho Bridge opened in November 2012, spanning the Mackenzie (Deh Cho) River, Fort Providence experienced temporary interruptions in road access during ice freeze-up and break-up.
} 
Indigenous people in Canada have experienced systematic assaults on their subsistence practices and ways of life. Education has moved from being largely "on the land" with family members to "in the classroom" with trained teachers. Land-based knowledge and practices have been curtailed by a separation from the land through the residential school system and the removal of cultural links to the land in school curricula (Miller, 1996; Milloy, 1999; Haig-Brown, 1988; Streit \& Mason, in press). Combined with other socio-economic pressures linked to government intervention and modernization, this has disrupted on-the-land experiential education processes, which are key to effective traditional knowledge transfer from elders to youth. This knowledge transfer gap means that youth often lack the necessary knowledge and skills to harvest and prepare wild foods (Robidoux, Haman, \& Sethna, 2009).

Sustained transmission of traditional knowledge and harvesting practices is essential for the continuity of wild food procurement processes. This is a challenge for many Indigenous communities, as parents may not possess the knowledge and skills to pass on to their youth. To enable younger generations to adapt and thrive under new and varied conditions, youth must be given opportunities to acquire basic land-based knowledge and skills through ongoing experiential learning (Pearce, Wright, Notaina, Kudlak, Smit, Ford, \& Furgal, 2011). Local schools have the opportunity to play a key role in building the capacity of Indigenous youth to be able to access the "bank" of food on the land if and when they need to, thus building resilience into the food system. While recent and ongoing improvements in northern school curricula are aimed at better incorporating Indigenous content and perspectives, the level of experiential learning about food procurement skills guided by Elders and land-users varies significantly by school and region. One way to address such gaps is to develop and implement land-based programs to build skills and knowledge around wild food harvesting in the context of environmental change. Two such programs are profiled below.

\section{Results: Land-based programs}

As outlined above, wild food access and production challenges are incredibly complex in northern Indigenous communities. While the programs discussed below were not designed to solve pressing food security or sovereignty issues, they aim to serve as a foundational block to promote integration of local land-based food programs into formal education systems and contribute to wider community health objectives. As noted by community leadership, the nutrition habits of parents in both communities vary considerably among and between families; regardless, a sizeable number of children rely on the schools to provide basic meals. As food security has come to the forefront as an important local issue, community leaders have been 
actively looking into ways to tackle this challenge. Their motivations to build supportive, skillsbased programs provided the impetus for the involvement of external partners. ${ }^{7}$

Since 2012 we have been working directly with the Principals at each of the local schools to support the development of community-based initiatives to improve wild food procurement as a method to increase access to healthy and local foods, especially for youth. In line with our previous research work with rural northern Indigenous communities, both in Canadian territories and provinces, we adopted a bottom-up approach for both NWT communities. We conducted initial visits to understand the needs of community members, in particular regarding their desire to build land-based programs and integrate them into the local school system. After initial visits and meetings with local band council members, Elders, knowledgeable land users, and staff from the schools, we worked collectively with community members to design and implement programs in the schools. In both cases, staff time was dedicated to these projects and funds were used to recruit local harvesters and Elders to work with the students. The selected projects are consistent with the intervention ideas identified by other global Indigenous communities interested in improving health through better food knowledge and access (Kuhnlein et al., 2006; Sharma, Gittelsohn, Rosol, \& Beck, 2010; Kolahdooz et al., 2014). Here we outline the evolution of each program to provide a basis for comparison and the identification of lessons learned.

\section{Fort Resolution}

The opportunity for developing a north-south partnership came at a critical time for Deninu School in Fort Resolution. The Principal, Dan Summers, spearheaded the partnership with our research team with the intention of extending existing “on-the-land” programming. He highlighted the importance and timeliness of the initiative:

Believe me, your program is going to have long-term effects. This is something we have been wanting to do for the last three or four years-getting into a net program.

As identified by community needs, the program began with two primary objectives: (1) to teach youth land-based food harvesting and preparation skills, and (2) to increase local consumption of wild foods. The funding supported the initiation of a local fishing program during winter months (December-March, 2012-2014). Initial funds were used to purchase supplies such as fish nets and gas for snowmobiles, and support the participation of several community harvesters. Under the supervision of local harvesters and school staff members, students from senior kindergarten class (age five) to grade 12 (age 17+) participated in the

\footnotetext{
${ }^{7}$ Our research team members were co-investigators on a Coalitions Linking Action for Science Prevention (CLASP) initiative, funded by the Canadian Partnership Against Cancer (CPAC). We worked with seven rural Indigenous communities across Canada to build and implement community-led land-based programs. Both Fort Providence and Fort Resolution decided that their local school would be the central node of their programs.
} 
process of setting fish nets under the ice on Great Slave Lake and harvesting fish from the nets. Through intergenerational knowledge sessions, harvesters and Elders shared knowledge about fish harvesting, preparation, and preservation methods, as well as the importance of sharing and consuming wild foods for health and cultural continuity. Ted Moes, a teacher who was integrally involved with the program, emphasized the value to the community:

Ice fishing is an ancient tradition in this community...having our kids active in the winter and on the land learning new skills and interacting with Elders is important to the survival of our culture, our language and even who we are as people.

During the first winter, the programs were hampered by unusually cold and windy conditions. A multi-week cold snap in December and another in January limited the time frame within which nets could be set and safely checked by students. This constrained student participation, especially for the younger grades. Regardless, the program still brought in considerable quantities of local fish (mainly whitefish, pickerel, northern pike, and lake trout). Some fish was consumed by students through the school's healthy snack program and the rest were stored in school freezers for distribution to community members. Following the first year of the program, Summers commented on how he imagined it progressing during the next season:

The kids get out there and help collect the net and the fish. And the next step after that is to have some of the older kids, particularly from the kitchen program, process some of the fish. We will have one or two Elders come in and they will help thaw and process the fish to get it ready for the smokehouse.

In the second year of the program, additional harvesting and processing equipment was acquired. Major purchases included a fish smoker and sleds for hauling gear and students. In year two, the weather proved to be less of an issue and all grades spent several days out on the ice. More than three times the initial amount of fish was harvested in the second season. The smokehouse, built on school property with the guidance of Elders, enabled students to learn about both traditional and modern smoking techniques, and participate in preserving the fish. Students participated in the entire food procurement process through the program, including setting nets, harvesting, preserving, packaging, and distributing hundreds of fish. In addition to providing for the school's healthy snack program, fish was also delivered to more vulnerable community members who had limited access to wild foods.

The program, led by staff members, Elders, and local harvesters, had some notable successes; however, there were also some significant challenges. Initially some community members expressed concern about contaminant levels in local fish from Resolution Bay, which lies adjacent to the community. Much of Great Slave Lake is considered a relatively pristine waterway and fish of most species are eaten regularly by local Indigenous and non-Indigenous 
populations; however, observed changes in water quality and quantity, combined with the largely unknown impacts of local community activities, legacy impacts from the nearby Pine Point mine (e.g contaminants leaching from waste piles), and downstream impacts of resource extraction and other industrial activity has raised questions about whether the fish are safe to eat. In response, the traditional knowledge program was linked with a scientific research project that included toxicological testing of fish caught during the first year of the program, which helped to alleviate concerns. Another challenge was related to mid-project changes in leadership at the school. However, multiple staff members had participated in and committed to pursuing the fishing program, thus reinforcing its resilience. Maintaining sustainable funding to establish more permanent programming is always an issue for small communities. As Moes alluded to, sustainability is critical for programs to reach their potential:

The biggest change that we have noticed is the youth excitement about being on the land and being involved in related programs...Having children excited about these programs that teach them critical skills and allow for important discussions about food security and community health is helping create a sustainable future of the programs and the community in general.

While sustainable resources for land-based programming is difficult for small Indigenous communities to secure within their limited human resources, once programs are formed, communities are often able to leverage funds from other sources. This is currently being pursued in Fort Resolution with local, regional, and southern partners (e.g., through research projects and government-supported programs).

\section{Fort Providence}

Similar to what transpired in Fort Resolution, the community consultation process in Fort Providence identified a number of critical objectives for the land-based program. In addition to the objectives of teaching youth land-based food harvesting skills and increasing local consumption of traditional foods, leaders and Elders also wanted to increase youth physical activity levels, support nutrition literacy for parents and youth, build relationships between the school and more traditional families in the community, and develop food distribution networks to ensure that vulnerable populations have access to local foods. To address these objectives, researchers, community members, and school staff worked together to implement multi-faceted programming. As was the case in Fort Resolution, the school became the centre of program activity. Deh Gah Elementary and Secondary School in Fort Providence implemented a multipronged wild foods snack program to engage students in learning about wild food harvesting through experiential education, and increase their consumption of these foods through a healthy snack program. The focus on building healthy habits is captured well by Lois Philipp, the school Principal: 
I think that if you look at the health implications of processed food in any Northern [Indigenous] population, it's going to be a tremendous impact at one point in terms of lifestyle, diabetes and all of that. So, if we can get them to build healthy habits and let youth see that relationship between diet, exercise and choice in the North - where we are much more blessed in the fact that we can go out our back doors and get our meal - if we can keep those skills up, then communities will always have a choice.

Initial funding was dedicated to program planning and the purchase of necessary equipment to allow the school to properly preserve snacks for the winter months. Investments were made in a vacuum sealer, jerky maker, smoker, and other tools to preserve locally caught fish and game. The school then worked to engage and build relationships with local harvesters who provided traditionally prepared foods to the school, led harvesting and food preparation activities with student groups on the land, and acted as resources during intergenerational knowledge sharing sessions. Students from senior kindergarten (age 5) to the senior high school (aged 17+) participated in harvesting and preparing wild foods, as well as consuming these foods through the school's snack program.

As was the case in Fort Resolution, the Fort Providence project provided the context for leveraging additional resources to extend the impact of local food procurement initiatives. This facilitated a university student to live in the community for a total of six months over numerous trips between May 2013 and February 2015. ${ }^{8}$ She worked with a Fort Providence high school student to facilitate the food procurement programs, beginning with a 2013 spring camp for youth on the land. While the program had ample buy-in from school staff and community members, the hamlet simply did not have the human or financial resources to dedicate a full-time worker to initiate the camp. The two students worked together to organize staff, students, resource providers, and community members to come together and work towards harvesting fish and waterfowl to preserve as snacks for the coming year.

Students from all classes had the opportunity, with parental consent, to spend time on the land. Over the course of the first six-week spring camp, approximately 70 percent of the school's 185 students participated outside of the classroom. Students engaged in all aspects of wild food procurement on a daily basis with program staff, Elders, and resource providers. The daily catch averaged 20 fish, including northern pike, whitefish, suckerfish, and pickerel. All students took turns helping to prepare the fish for smoking over the fire. Lunch consisted of wild foods—often fresh waterfowl supplied by local resource providers - that students helped prepare and cook over the campfire. In addition to encouraging students to acquire a taste for these foods, they were also taught the importance of connecting with their roots, preparing traditional meals, and respecting the land and the food it provided. The Elders shared stories with the youth and taught traditional games, skills and values. For some students, spring camp and other school outings

\footnotetext{
${ }^{8}$ Funding for the university student was provided by the University of Ottawa's Students for Canada's North Program.
} 
were the only opportunities they had to spend time on the land. Elder and guidance counsellor Margaret Thom emphasized the importance of the spring camps for local youth:

By giving these camps focus and direction, youth were able to develop skills that are important to our culture and way of life. Our students show signs of increased self-esteem and community relationships through these skills.

A significant exchange of knowledge took place over the six-week period as students became more accustomed to processing the fish and waterfowl. In addition to the daily wild food meals consumed at the camp, the students were able to preserve over 300 fish for the upcoming winter months to provide for the school snack program.

In the fall of 2013, the programs were expanded to include the fall and winter harvest. High school students traveled a considerable distance from the community down the Mackenzie River by canoe with Elders, community members, and school staff. They learned from and with local experts on the land while gaining course credit. In addition to identifying and harvesting edible plants and medicines (including wild mint, spruce gum, sweetgrass, Labrador tea leaves, high and low bush-cranberries, and birch paper) from the land, they also processed fish and waterfowl to be preserved for the school snack program. In the winter, the focus turned to setting rabbit snares and beaver traps as well as ice fishing. All of these programs were repeated in the second year (2014) with increased levels of participation and yields.

Despite its successes, the wild foods snack program also encountered several challenges. One barrier to winter harvesting related directly to the geography of the community. To set fishing nets under the ice, residents are required to travel a fair distance, which requires significant time investment and planning, especially when students are involved. This contrasts with Fort Resolution, which is situated directly on the shore of Great Slave Lake (see Figure 1). Another notable challenge was the limited level of parental involvement in the school's snack program activities, despite outreach and engagement efforts. As in many small rural Indigenous communities, locally-available human resources were limited and stretched to capacity; however, these are essential for program continuity and sustainability. While there was ample buy-in to the wild foods snack program by key school staff members and resource providers, many are overburdened by other-often employment-related—commitments.

\section{Discussion: Building relationships and capacity for Indigenous food security}

The intent of the profiled land-based wild food programs is to contribute to food security and community well-being in multiple ways (Table 1), as highlighted by Fort Providence's Vice Principal Jim Snider: 
We have been able to build relationships with community members, Elders and parents who have strong land-based skill sets that are now acknowledged and privileged within an educational institution. While bringing food access to the community has been a great benefit, the relationship building that the funding has facilitated is extremely beneficial and will continue to have positive effects.

Each program addressed a range of aspects of wild food procurement, including education, cultural continuity, social networks, consumption, and distribution, which relate to specific food security pillars. These programs increase both access to and use of wild foods at the local scale, whereas wild food availability and quality often rely on broader processes of wildlife and environmental management. As such, these programs acted as holistic local-scale adaptation strategies in the face of environmental change. Their impact goes beyond simple capacity-building for increased food access, and should therefore be evaluated in the broader socio-cultural community context that recognizes contributions to relationship-building, knowledge transmission, and cultural continuities.

Table 1: Contribution of Land-Based Programs to Community Food Security and Well-Being

\begin{tabular}{|c|c|c|}
\hline Well-being element & Activity & Food Security Pillar \\
\hline Education & $\begin{array}{l}\text { - Increased knowledge of wild food } \\
\text { harvesting, preparation and consumption } \\
\text { for youth }\end{array}$ & $\begin{array}{l}\text { - Improved food use through } \\
\text { knowledge sharing }\end{array}$ \\
\hline Cultural continuity & $\begin{array}{l}\text { - Supported land-based initiatives and local } \\
\text { cultural and linguistic practices } \\
\text { - Facilitated inter-generational knowledge } \\
\text { sharing between Elders and youth }\end{array}$ & $\begin{array}{l}\text { - Improved food use through } \\
\text { knowledge sharing }\end{array}$ \\
\hline Social networks & $\begin{array}{l}\text { - Facilitated relationships between } \\
\text { harvesters, staff and children at the school }\end{array}$ & $\begin{array}{l}\text { - Improved food use through } \\
\text { knowledge sharing } \\
\text { - Increased access to wild foods }\end{array}$ \\
\hline Food consumption & $\begin{array}{l}\text { - Provided wild foods to youth and } \\
\text { community members }\end{array}$ & - Increased access to wild foods \\
\hline Food distribution & $\begin{array}{l}\text { - Formalized distribution methods for wild } \\
\text { foods in the community }\end{array}$ & - Increased access to wild foods \\
\hline
\end{tabular}

Through our experience with these two community programs in Fort Providence and Fort Resolution, NWT, our research team-in collaboration with community partners-identified several key factors that contributed to successful outcomes. Both of the abovementioned landbased programs were developed to fit the specific, unique local context. They were built around local values and customs, helping community members to reclaim cultural practices and convey 
foodways knowledge to younger generations. Creating linkages between Elders and youth is an effective way to bridge the existing knowledge transmission gap. A focus on reclaiming cultural practices and supporting cultural continuity incentivizes community member engagement, particularly when youth are involved. In this context, addressing aspects of health and wellbeing, as well as food autonomy (which is related to self-determination), speak to issues of key importance for both individuals and the community at large.

It is important for the focus on youth to be explicit, regardless of whether youth is the primary target group or an identified component thereof. Working with younger generations has multiple advantages, including the development of a "taste" for wild food early in life, normalization of wild food as part of a healthy diet, and the de-stigmatization of wild foods which may be seen by some as inferior and anti-modern (Robidoux et al., 2009). It is also likely that youth will share knowledge with other family members and friends, thus providing a knowledge translation mechanism at the community scale. Among other benefits, these programs contribute to strengthening culture and social ties, contribute to the physical health of students in the community, and also support increased food autonomy through local capacity-building. By engaging students and other community members over a multi-year period, such programs become part of the positive culture of the school and community, thus activating existing resources (e.g., volunteer work by community members, dedicated student work as part of their community service hours, and summer internships).

The community-directed nature of these local food procurement programs provides a foundation for the successes achieved in each community. Programs must be community-led to ensure that they respond to local needs and are feasible in the existing context. In both case studies, the school Principals had a passion for land-based education, a vision for how to improve it, and the ability to integrate program activities into the existing curriculum. These individuals committed considerable time and resources to planning, implementation, and reporting, including both financial and logistical aspects. Key staff members at both schools were also integral to program success, as was the interest and motivation of knowledgeable Elders and harvesters. It is essential that such programs have a community champion and dedicated human resources at the local level. Ideally a team of community champions would be established to share roles and time commitment, and provide continuity in case of changes in leadership.

In both case studies, project funds were used to leverage additional funds from other sources, both by the research team (e.g., internal university programs and external research assistant support) and by the community partner (e.g., territorial government funding). This improved program alignment with other activities enabled the extension of program activities where needed and provided a basis for program sustainability. This ability to seek out and capitalize on complementary funding opportunities requires flexibility and an ability to think creatively about how to effectively build on the initial program and realize additional benefits. Strong community-academic partnerships can expand the potential for leveraging from different sources. 
When dealing with wild food procurement, the aspect of seasonality is an essential consideration. Harvesting timeframes vary by species and season, and are often fairly specific. Thus, it is imperative that the timing and logistics are well planned and communicated to ensure that they match local conditions and harvester availability, while also ensuring compatibility with funding regulations and deadlines. At the same time, program partners and associated funders must be adaptable and responsive to local priorities and changing circumstances, such as program changes due to weather and cycles of turnover in local leadership.

Sustainability is a key challenge for community-based wild food programs in northern communities, as they rely on continued funding and community engagement. While good ideas can stimulate action, certain conditions must be in place to implement effective programming. Despite certain similarities, each northern Indigenous community provides a unique context, thus limiting the utility of a one-size-fits-all approach. At the same time, the complexity of food security issues requires a multi-faceted approach. Intervention programs require both initial capital input as well as a longer term plan for continuity. Program design must be considered from the beginning to ensure that sustainability planning is both incorporated and feasible. Additionally, accountability is critical when using government funds. Program coordinators require an effective system for documenting expenses and maintaining open and transparent communication throughout the process. A related aspect is the need to address potentially competing visions within the community. Broad community support is required for program sustainability over the long term, thus requiring transparent and open dialogue among interested stakeholders.

More specifically, the program in Fort Providence has achieved a level of sustainability, due to several key factors: a) the commitment, passion and longevity of a dedicated community champion; b) existing momentum and a positive culture relating to land-based education practices; c) the availability of and capacity to access and leverage resources (financial, human), as well as flexibility, openness, and a willingness to engage with external people and processes; d) a reasonable level of autonomy of the partner organization (e.g., the school) to implement the program and connect it to other activities. The community-based approach was essential to achieving this, as it allowed participants to identify needs and allocate resources in appropriate ways.

\section{Conclusion}

Environmental change in the upper Mackenzie River Basin has significant impacts on food security, human health, and well-being, as well as links to cultural identity (Wesche \& Armitage, 2006). Clearly, northern communities must implement adaptation measures to increase food security and maintain well-being in the face of climate change and other stressors. Communitydriven programming can offer an effective mechanism through which to build local capacity for wild food procurement, and schools can play a key role. At the same time, efforts must be made 
to overcome barriers and ensure the effectiveness of intervention programs. While changing social and environmental conditions create diverse challenges for the current generation, targeted programs can support the acquisition and application of traditional knowledge and skills for residents of all ages. A focus on land-based activities and connections with the land can also play a key role in addressing root causes of current challenges to social cohesion and well-being (Pearce et al., 2011; Anuik, Battiste, \& George, 2010; Samson \& Pretty, 2006; Mason, 2014; Takano, 2005; Alfred, 2005; Alfred, 2009). As a result, the "land" in and around communities offers an excellent and often under-utilized educational resource.

Kuhnlein et al. (2006) highlight the importance of taking a grassroots approach to building local capacities to address local concerns. This encourages community engagement, allows for the inclusion of traditional knowledge, and improves the likelihood of success of local programs. Existing culturally-relevant programming in community schools (e.g., related to language, sewing, or traditional knowledge) offers an excellent foundation for developing community-driven programming around wild food procurement. While both diversifying the curriculum and increasing local relevance, the resulting programs may also help to counteract current under-utilization of local knowledge and wild food resources, thus effectively expanding access to the existing resource base.

A diverse range of possible interventions are available to individual communities at any point in time. To ensure effectiveness, our partner communities emphasized that programs must be bottom-up, ensure that local champions and resources are in place, effectively target specific community sub-groups, and remain culturally appropriate and viable considering existing priorities. The stability of food resources over time is also an important parameter, thus adaptive strategies must be sustainable to ensure long-term effectiveness.

The case studies presented here offer insights for the development of effective wild food procurement programs. While these types of programs are no panacea for local food security issues, they are part of an evolving strategy to manage and respond to the changes encountered by communities. While providing some short-term benefits around increased food access and caloric intake for youth and community members, such programs should really be seen as longterm investments to influence how individuals and communities think about and approach food procurement, thus helping to rebuild local food systems and sovereignty. In this context, both communities and researchers should recognize the value of partnerships that bring together complementary interests and expertise to address pressing food security issues (Andrée et al., 2014). At the same time, many Indigenous communities are facing similar food security challenges in other parts of the world, and may benefit from the insights presented here.

\section{Acknowledgements}

A very heartfelt Mahsi Cho to all of the Elders, harvesters, students, school staff and community members who shared their time and knowledge during this project. We also thank Karine Saboui 
for her help with Figure 1 and two anonymous reviewers for their constructive comments. Funding for this project was provided by the Canadian Partnership Against Cancer (CPAC), the University of Ottawa’s Students for Canada’s North Program, and the Aurora Research Institute.

\section{References}

ACIA (2005). Arctic Climate Impact Assessment. Cambridge: Cambridge University Press.

Alfred, T. (2005). Wasáse: Indigenous Pathways of Action and Freedom. Toronto: University of Toronto Press.

Alfred, T. (2009). Colonialism and State Dependency.” Journal de la Santé Autochtone, 5, $42-60$.

Andrée, P., Chapman, D., Hawkins, L., Kneen, C., Martin, W., Muehlberger, C., Nelson, C., Pigott, K., Qaderi-Attayi, W., Scott, S., \& Stroink, W. (2014). Building Effective Relationships for Community-Engaged Scholarship in Canadian Food Studies. Canadian Food Studies, 1(1), 27-53.

Anuik, J., Battiste, M., \& George, P. (2010). Learning from Promising Programs and Applications in Nourishing the Learning Spirit. Canadian Journal of Native Education, 33(1), 63..

Battiste, M., \& Youngblood Henderson, J. (Sa’ke’j) (2000). Protecting Indigenous Knowledge and Heritage. Knowledge and Heritage: A Global Challenge: Purich Publishing.

Bishop, R. (2005). Freeing Ourselves from Neocolonial Domination in Research. In N. Denzin and Y. S. Lincoln (Eds.), The Sage Handbook of Qualitative Research (pp. 109-138). Thousand Oaks: Sage Publishing.

Brock, B.E., Martin, M.E., Mongeon, C.L., Sokal, M.A., Wesche, S.D., Armitage, D., Wolfe, B.B., Hall, R.I., \& Edwards, T.W. (2010). Flood Frequency Variability During the Past 80 Years in the Slave River Delta, NWT, as Determined from Multi-Proxy Paleolimnological Analysis. Canadian Water Resources Journal, 35(3), 281-300.

Council of Canadian Academies (2014). Aboriginal Food Security in Northern Canada: An Assessment of the State of Knowledge. Council of Canadian Academies. Retrieved from http://www.scienceadvice.ca/en/assessments/completed/food-security.aspx

Desmarais, A.A. (2015). The Gift of Food Sovereignty. Canadian Food Studies, 2(2), 154-163.

FAO (1996). Rome Declaration on World Food Security and World Food Summit Plan of Action. FAO. Retrieved from www.fao.org/docrep/003/w3613e/w3613e00.htm 
Fillion, M., Laird, B., Douglas, V., Van Pelt, L., Archie, D., \& Chan, H.M. (2014). Development of a Strategic Plan for Food Security and Safety in the Inuvialuit Settlement Region, Canada. International Journal of Circumpolar Health, 73, 25091.

Fumoleau, R. (2004). As Long as this Land Shall Last: A History of Treaty 8 and Treaty 11, 1870-1939. Calgary: University of Calgary Press.

Gerlach, S.C., \& Loring, P.A. (2013). Rebuilding Northern Foodsheds, Sustainable Food Systems, Community Well-Being, and Food Security. International Journal of Circumpolar Health, 72, 1-4.

Haig-Brown, C. (1988). Resistance and Renewal: Surviving the Indian Residential School. Vancouver: Tillacum Library, Arsenal Press.

Hamlet of Fort Providence (2013). History and Culture. Fort Providence. Retrieved from http://fortprovidence.lgant.ca/community/history-and-culture-9

Kolahdooz, F., Pakseresht, M., Mead, E., Beck, L., Corriveau, A., \& Sharma, S. (2014). Impact of the Healthy Foods North Nutrition Intervention Program on Inuit and Inuvialuit Food Consumption and Preparation Methods in Canadian Arctic Communities. Nutrition Journal, 13(1), 68.

Kovach, E.M. (2010). Indigenous Methodologies: Characteristics, Conversations, and Contexts. Toronto: University of Toronto Press.

Kuhnlein, H.V., Erasmus, B., Creed-Kanashiro, H., Englberger, L., Okeke, C., Turner, N., Allen, L., \& Bhattacharjee, L. (2006). Indigenous Peoples’ Food Systems for Health: Finding Interventions that Work. Public Health Nutrition, 9(8), 1013-1019.

Kuhnlein, H.V., \& Receveur, O. (2007). Local Cultural Animal Food Contributes High Levels of Nutrients for Arctic Canadian Indigenous Adults and Children. The Journal of Nutrition, 137(4), 1110-1114.

Kuhnlein, H.V., Receveur, O., Soueida, R., \& Egeland, G.M. (2004). Arctic Indigenous Peoples Experience the Nutrition Transition with Changing Dietary Patterns and Obesity. The Journal of Nutrition, 134(6), 1447-1453.

Loring, P.A., \& Gerlach, C. (2009). Food, Culture, and Human Health in Alaska: an Integrative Health Approach to Food Security. Environmental Science \& Policy, 12(4), 466-478.

Mason, C.W. (2014). Spirits of the Rockies: Reasserting an Indigenous Presence in Banff National Park. Toronto: University of Toronto Press.

Miller, J.R. (1996). Shingwauk's Vision: A History of Native Residential Schools. Toronto: University of Toronto Press. 
Milloy, J.S. (1999). A National Crime: The Canadian Government and the Residential School System, 1879 to 1986. Calgary: University of Manitoba Press.

Northwest Territories Bureau of Statistics (2011a). Community Price Indexes. Northwest Territories Bureau of Statistics. Retrieved from http://www.statsnwt.ca/pricesexpenditures/community-price-index

Northwest Territories Bureau of Statistics (2011b). Fort Providence-Statistical Profile. Northwest Territories Bureau of Statistics. Retrieved from http://www.statsnwt.ca/community-data/Profile PDF/Fort Providence.pdf

Northwest Territories Bureau of Statistics (2011c). Fort Resolution-Statistical Profile. Northwest Territories Bureau of Statistics. Retrieved from http://www.statsnwt.ca/communitydata/Profile PDF/Fort Resolution.pdf

Nunavut Food Security Coalition (2014). Nunavut Food Security Strategy and Action Plan 201416. Retrieved from http://www.tunngavik.com/files/2014/05/NunavutFoodSecurityStrategy_ENGLISH.pdf

Organ, J., Castleden, H., Furgal, C., Sheldon, T., \& Hart, C. (2014). Contemporary Programs in Support of Traditional Ways: Inuit Perspectives on Community Freezers as a Mechanism to Alleviate Pressures of Wild Food Access in Nain, Nunatsiavut. Health \& Place, 30, 251-259.

Pal, S., Haman, F., \& Robidoux, M.A. (2013). The Costs of Local Food Procurement in Two Northern Indigenous Communities in Canada. Food and Foodways, 21(2), 132-152.

Pearce, T., Wright, H., Notaina, R., Kudlak, A., Smit, B.., Ford, J., \& Furgal C. (2011). Transmission of Environmental Knowledge and Land Skills among Inuit Men in Ulukhaktok, Northwest Territories, Canada. Human Ecology, 39(3), 271-288.

Reading, C.L., \& Wien, F. (2009). Health Inequalities and the Social Determinants of Aboriginal Peoples' Health. Prince George, BC: National Collaborating Centre for Aboriginal Health.

Receveur, O., Boulay, M., \& Kuhnlein, H.V. (1997). Decreasing Traditional Food Use Affects Diet Quality for Adult Dene/Métis in 16 Communities of the Canadian Northwest Territories. The Journal of Nutrition, 127(11), 2179-2186.

Robidoux, M.A., Haman, F., \& Sethna, C. (2009). The Relationship of the Burbot (Lota lota L.) to the Reintroduction of Off-The-Land Foods in the Sandy Lake First Nation Community. Biodemography and Social Biology, 55(1), 12-29.

Ruelle, M.L., \& Kassam, K.A.S. (2013). Foodways Transmission in the Standing Rock Nation. Food and Foodways, 21(4), 315-339. 
Samson, C. \& Pretty, J. (2006). Environmental and Health Benefits of Hunting Lifestyles and Diets for the Innu of Labrador. Food Policy, 31(6), 528-553.

Sharma, S., Gittelsohn, R.R., \& Beck, L. (2010). Addressing the Public Health Burden Caused by the Nutrition Transition Through the Healthy Foods North Nutrition and Lifestyle Intervention Programme. Journal of Human Nutrition and Dietetics, 23(s1), 120-127.

Skinner, K., Hanning, R.M., Desjardins, E., \& Tsuji, L.J. (2013). Giving Voice to Food Insecurity in a Remote Indigenous Community in Subarctic Ontario, Canada: Traditional Ways, Ways to Cope, Ways Forward. BMC Public Health, 13(1), 427.

Smith, D.M. (1982). Moose-Deer Island House People: A History of the Native People of Fort Resolution. Musée National de l'Homme. Collection Mercure. Division d'Ethnologie. Service Canadien d'Ethnologie. Dossier Ottawa, 81, 1-185.

Smith, L.T. (1999). Decolonizing Methodologies: Research and Indigenous Peoples. London: Zed Books.

Streit, D., \& Mason, C.W. (In press). Traversing the Terrain of Land-Based Education and Health for First Nations Youth: Connecting Theory to Practical Program Development. In M.A. Robidoux and C.W. Mason (Eds.), A Land Not Forgotten: Indigenous Food Security and Land-Based Practices of Northern Ontario (pp.101-147). Winnipeg: University of Manitoba Press.

Takano, T. (2005). Connections with the Land: Land-Skills Courses in Igloolik, Nunavut. Ethnography, 6(4), 463-486.

Wesche, S.D. (2009). Responding to Change in a Northern Aboriginal Community (Fort Resolution, NWT, Canada): Linking Social and Ecological Perspectives. PhD Dissertation, Wilfrid Laurier University.

Wesche, S., \& Armitage, D. (2006). Adapting to Environmental Change in a Northern Delta System. In R. Riewe and J. Oakes (Eds.), Climate Change: Linking Traditional and Scientific Knowledge, (pp. 105-120). Winnipeg: Aboriginal Issues Press.

Wesche, S., \& Armitage, D. (2010). 'As Long as the Sun Shines, the Rivers Flow and Grass Grows': Vulnerability, Adaptation and Environmental Change in Deninu Kue Traditional Territory, Northwest Territories. In G.K. Hovelsrud and B. Smit (Eds.), Community Adaptation and Vulnerability in Arctic Regions (pp. 163-189). Dordrecht: Springer.

Wesche, S.D., \& Chan, H.M. (2010). Adapting to the Impacts of Climate Change on Food Security among Inuit in the Western Canadian Arctic. EcoHealth, 7(3), 361-373. 
Wolfe, B.B., Armitage, D., Wesche, S., Brock, B.E., Sokal, M.A., Clogg-Wright, K.P., Mongeon, C.L., Adam, M.E., Hall, R.I., \& Edwards, T.W. (2007). From Isotopes to TK Interviews: Towards Interdisciplinary Research in Fort Resolution and the Slave River Delta, Northwest Territories. Arctic, 60(1), 75-87.

Yip, Q.K., Burn, D.H., Seglenieks, F., Pietroniro, A., \& Soulis, E.D. (2012). Climate Impacts on Hydrological Variables in the Mackenzie River Basin. Canadian Water Resources Journal, 37(3), 209-230.

\section{Interviews}

Balsillie, Don. Personal Interview. 16 August 2005.

Beaulieau, Angus. Personal Interview. 5 July 2005.

Delorme, Kenneth. Personal Interview. 26 June 2005.

Francis, Nancy. Personal Interview. 29 January 2015.

Landry, Rudolph. Personal Interview. 21 August 2013.

Mandeville, Harvey. Personal Interview. 6 August 2005.

Matto, Theodore. Personal Interview. 22 October 2012.

McKay, Denise. Personal Interview. 14 December 2005.

Moes, Ted. Personal Interview. 14 May 2013.

Moes, Ted. Telephone Interview. 18 April 2014.

Philipp, Lois. Personal Interview. 19 February 2013.

Philipp, Lois. Personal Interview. 09 May 2013.

Snider, Jim. Personal Interview. 10 May 2013.

Summers, Dan. Personal Interview. 20 February 2013.

Summers, Dan. Personal Interview. 13 May 2013.

Thom, Margaret. Personal Interview. 09 May 2013.

Trudeau, Denise. Personal Interview. 9 February 2015.

Wright, Greg. Personal Interview. 01 February 2015.

Yelle, Gabe. Personal Interview. 20 June 2005. 